\title{
Erratum: The pressing energy innovation challenge of the US National Laboratories
}

Laura Diaz Anadon, Gabriel Chan, Amitai Y. Bin-Nun and Venkatesh Narayanamurti

Nature Energy 1, 16117 (2016); published 12 September 2016; corrected 24 October 2016.

When this Perspective was published it should have been accompanied by a Supplementary Data file. This file has now been uploaded. 